\title{
Some reasons for decreased service time of dies for Al hot extrusion
}

\author{
P. Fajfar ${ }^{1}$, P. Panjan ${ }^{2}$, G. Kugler ${ }^{1}$ \& M. Terčelj ${ }^{1}$ \\ ${ }^{1}$ Department of Materials and Metallurgy, Faculty of Natural Sciences \\ and Engineering, University of Ljubljana, Slovenia \\ ${ }^{2}$ Institute of Jožef Štefan, Ljubljana, Slovenia
}

\begin{abstract}
In this contribution some important reasons for decreased service time of selected nitrided and coated dies for $\mathrm{Al}$ extrusion are explained. The influences of contact pressure, length of bearing surface, nitriding conditions and of the preparation of inlet edge of bearing surface at PVD CrN coating were studied. Laboratory tests of the wear at lower and increased contact pressure and an analysis of the wear on industrial dies were carried out. The die design and the flow of the extruded material should lead to a decrease of the contact pressure on the bearing surface. Two different modes of the initial wear progress on the area at the exit edge of the bearing surface were observed. Despite good adhesional and other relevant characteristics of $\mathrm{CrN}$ coating, the analysis revealed that inappropriate construction of the initial edge of the die bearing surface in combination with the maintenance of the die seems to be the main reasons for a considerably decreased service time of these dies as expected.
\end{abstract}

Keywords: Al hot extrusion, nitrided dies, $\mathrm{Cr}$ coatings, service time, wear analysis.

\section{Introduction}

Aluminum hot extrusion is a process of metal forming done on a hydraulic press where heated billet is pushed by a ram through a profile opening of die which gives extruded profile the desired shape, dimensions and surface finish. In this manner, different products like rods, beams, wires, tubes, etc. with different dimensions can be produced. Beside extrusion speed and billet temperature, damages on die bearing surfaces have a decisive influence on the surface finish 
of the extruded profiles. Thus surface finish in relation to the shape and the required cross-sectional dimensions of extruded profile determines the service time of dies [1-4].

H10, H13 and H11 die steels are usually used for dies for Al hot extrusion. There are a lot of parameters which influence the service time of nitrided dies, i.e. die construction (design) and flow of material, loads (mechanical, thermal, tribological and chemical), wear resistance of nitrided layer which is related to the heat treatment and the initial quality of die steel as well as parameters related to nitriding process (previous surface preparation and nitriding parameters which influence characteristics of compound and diffusion layer, etc.), die maintenance, chemical composition of extruded material, etc. Values of parameters related to tribological loads on bearing surfaces are: contact pressures bellow $30 \mathrm{MPa}$, temperature of $\mathrm{Al}$ at profile surface up to $600^{\circ} \mathrm{C}$, extrusion profile speed up to $100 \mathrm{~m} / \mathrm{min}$; adhesion, abrasion and chemical reaction are the prevailing wear mechanisms [5-13]. For the prolongation of die service time in ca. 94\% of cases gas nitriding is used, while the coating procedures are, due to "line-of-sight" effect in narrow gaps of dies, applied in lower cases. Roughly, PVD coated dies can achieve approximately eight times longer service time in comparison to nitrided dies. Since nitrided dies are also renitrided up to eight times their service times are thus comparable to those of surface coated dies [1, 4, 14]. Variations in service times of similar and same dies from the point of view of nitriding, contact pressure and bearing surface length of dies are not sufficiently explained; moreover, dies can also exhibit considerably lower service time as expected [8, 12, 15-17]. For this purpose, it is important to obtain relevant data on wear progress already in the early stage of degradation process since better explanation of the degradation progress is assured like this. These data can also be obtained from laboratory wear testing if similarity of tribological systems in laboratory and industry is established. In general, it is supposed that contact pressures on the die bearing surface are related to the die construction, shape and dimensions of the extruded profile; furthermore, it is also supposed that the contact pressure also changes around the die bearing surface perimeter and along the bearing surface length.

In this contribution, the results obtained in laboratory wear testing of nitrided samples and the results of the wear analysis of three industrial dies are given. Thus the results of the analysis of the early stage of the degradation process in laboratory testing of the wear will be presented and combined with the analysis of wear of the industrial dies.

\section{Experimental}

\subsection{Laboratory tests}

Laboratory wear testing simulating a tribological system occurred in Al hot extrusion was carried out; "block on cylinder" configuration was used (see Figure 1). The rotating cylinder with dimensions $\Phi 146 \mathrm{~mm}$ x $35 \mathrm{~mm}$ made of Al-alloy represents the extruded part, while the block with dimension $30 \mathrm{~mm} \mathrm{x}$ 
$30 \mathrm{~mm}$ x $20 \mathrm{~mm}$ represents the nitrided die. The chemical composition of the $\mathrm{Al}$ cylinder (AA6063) was Mg-0.5 wt\%, Si-0.5 wt\%, Fe-0.19 wt\%, Mn-0.05 wt\% with the balance being Al. Al cylinder was heated to around $550{ }^{\circ} \mathrm{C}$, sliding velocity was $0.5 \mathrm{~m} / \mathrm{s}$, normal load on nitrided samples amounted to $1920 \mathrm{~N}$. Al cylinder is heated via a heating coil, i.e. in radial direction from outside, as well as via steel discs, i.e. in radial direction from inside. Thus using different heat supplies; i.e. from inside and from outside on the Al cylinder at approximately similar outside temperature (i.e. test temperature) this results in different temperature field on $\mathrm{Al}$ cylinder in radial direction and consequently also in different established contact length between heated $\mathrm{Al}$ cylinder and tested blocks. In our case, contact lengths of $13 \mathrm{~mm}$ and $10 \mathrm{~mm}$, respectively, were used while testing. The wear tests were interrupted after $30 \mathrm{~min}, 60 \mathrm{~min}$ and 120 min of testing.

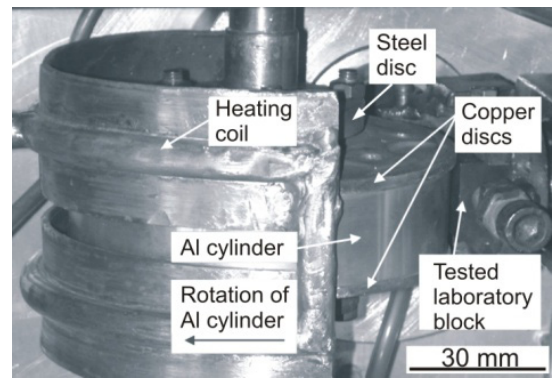

Figure 1: "Block on cylinder" assembly for the testing of wear of nitride blocks.

\subsection{Microstructure of applied blocks and dies}

Wear tests were carried out on nitrided blocks made from H10 and H13 die steels. Two different microstructures on tested blocks (see Figure 2(a) and (b)) were used for the wear testing to reveal the early stage characteristics of the wear progress; thus the influence of quality of microstructure has been estimated. Microstructure on bearing surface of analyzed dies after fifth renitriding cycle is given in Figure 2(c).

Microstructures of nitrided samples were obtained with an OLYMPUS BX60M optical microscope (nital etchant was applied). Phase compositions of compound layer on nitrided samples were obtained by X-ray diffraction (XRD) measurements on Siemens Analytical D5000 diffractometer with a Cu anode. In order to carry out the observation of the wear progress on tribologically loaded surfaces after each test sequence, the stuck $\mathrm{Al}$ on tested blocks was removed in $\mathrm{NaOH}$ solution. The degradation progress of the compound layer was identified with scanning electron microscopy (SEM) and back-scattered electron microscopy (BSE) using a JEOL JSM 5610 microscope. 

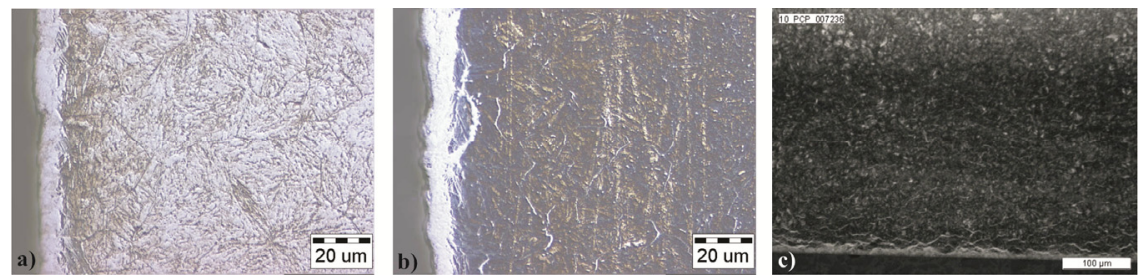

Figure 2: $\quad$ Microstructure of nitrided blocks; microstructure of block 1 (H13) (a) and of block 2 (H10) (b) and dies after the fifth renitriding (H13) (c).

\subsection{Applied dies for the analysis of the wear}

Analysis of wear was performed on three industrial dies (H13), i.e. die 1 (see Figure 3(a)) with a shorter $(3.5 \mathrm{~mm}$ ) bearing surface and die 2 (see Figure 3(b)) with a longer $(5 \mathrm{~mm}$ ) bearing surfaces; both dies were renitrided five times. The third die (see Figure 3(c)) was PVD coated with the length of the bearing surface of 5.5mm.Extruded profiles were hollow with thickness of walls of $1.5 \mathrm{~mm}$.

As mentioned above, it was reasonable to suppose that at all dies contact pressures around the bearing surface perimeters (i.e. perpendicular to the sliding direction) and along the lengths of the bearing surfaces; i.e. in the sliding direction, change and, consequently, the wear progress is also likely to be different. Thus with regards to the die design (shape of profile, etc.), aluminum flow, areas with relatively lower and areas with relatively slightly increased contact pressures were assumed. Additionally, die steel properties and the quality of the nitrided layer are not constant on the entire bearing surface. This leads to differences regarding the wear progress on the die bearing surface that can enable its reconstruction (estimation).
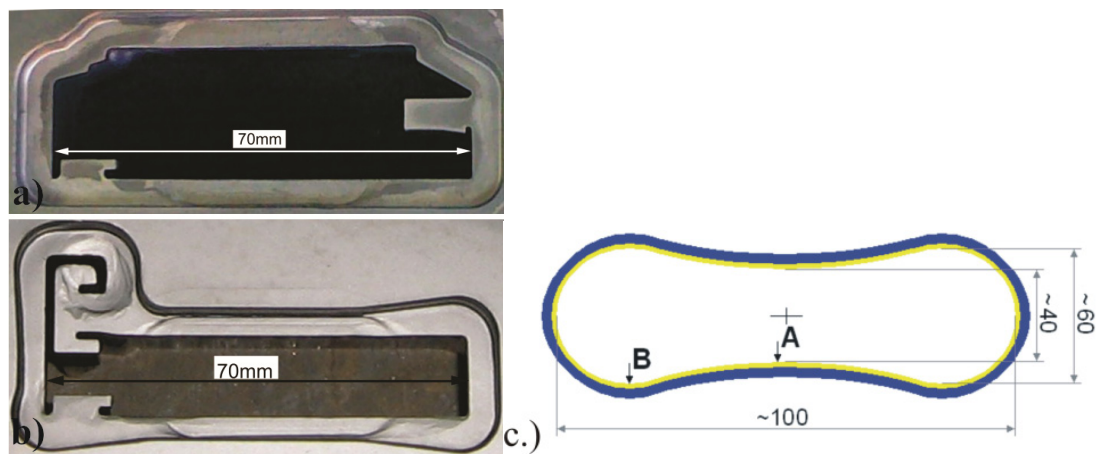

Figure 3: Applied dies (profiles, wall thickness $1.5 \mathrm{~mm}$ ) for the analysis of the wear progress, die 1 (a), die 2 (b) and die 3 (c). 


\section{Results}

\subsection{Microstructures of the nitrided samples and dies}

On all nitrided blocks, the compound layer was formed on the surface (see Figure 2(a) and (b)). It is clearly visible that almost no nitrides can be found on grain boundaries on the block 1 (Figure 2(a)), while on the block 2 (Figure 2(b)) this was the case. XRD measurement revealed that on both samples, the compound layer is predominately composed of $\varepsilon$ phase which is harder in comparison to $\gamma$ ' phase.

Microstructure of nitrided bearing surface of dies (Figure 2(c)) is also characterized by the presence of the compound layer on its surface and nitrides on the grain boundaries; but in this case, the XRD measurements revealed predominately $\gamma$ ' phase composition of the compound layer. This could indicate on its decreased hardness.

Furthermore, also good adhesional properties for CrN coating were obtained $\left(\mathrm{Lc}_{5}=90 \mathrm{~N}\right)$.

\subsection{Main characteristics of laboratory wear testing}

Different modes of the wear progress were observed regarding the applying of lower and slightly increased contact pressure, while a different wear rate at a similar mode of the wear progress is related to a different quality of microstructures. In Figures 4 and 5, the main characteristics regarding the testing at relatively lower and slightly increased contact pressures after one and two hours of testing for two different qualities of microstructure of nitrided blocks are shown. Thus for one hour of testing, it is visible that at a lower contact pressure (Figure 4(a)) the density of islets of the removed compound layer is lower in comparison to higher contact pressure (Figure 4(b)). In the case where a better quality of the compound layer is applied, the density of removed islets is lower since its removal takes place predominately partly on the base of adhesional removal of the compound layer and partly also due to its cracking (see Figure 4(c)). On the other hand, in the case of a lower quality of the compound layer, i.e. due to the presence of increased porosity, additional mechanism at the compound layer degradation takes place resulting in increased density of removed islets of the compound layer; due to locally increased porosity in the compound layer, its cracking and adhesional removal occur (see Figure 4(d) and (e)).

On Figures 5(a) and (b), the states of tribologically loaded surface after two hours of testing for relatively higher and lower contact pressure, respectively, are presented. It is clearly seen that the wear rate at a higher contact pressure is higher in comparison to a lower contact pressure (see details in Figures 5(c)) and at this stage, no in sliding direction oriented removal of the compound layer takes place. But in later stages (after 3-4 hours of testing), this occurred during testing at a slightly higher contact pressure, as presented in Figure 5(d). These results indicate the importance of the decreasing of contact pressure on the bearing surfaces of dies. 

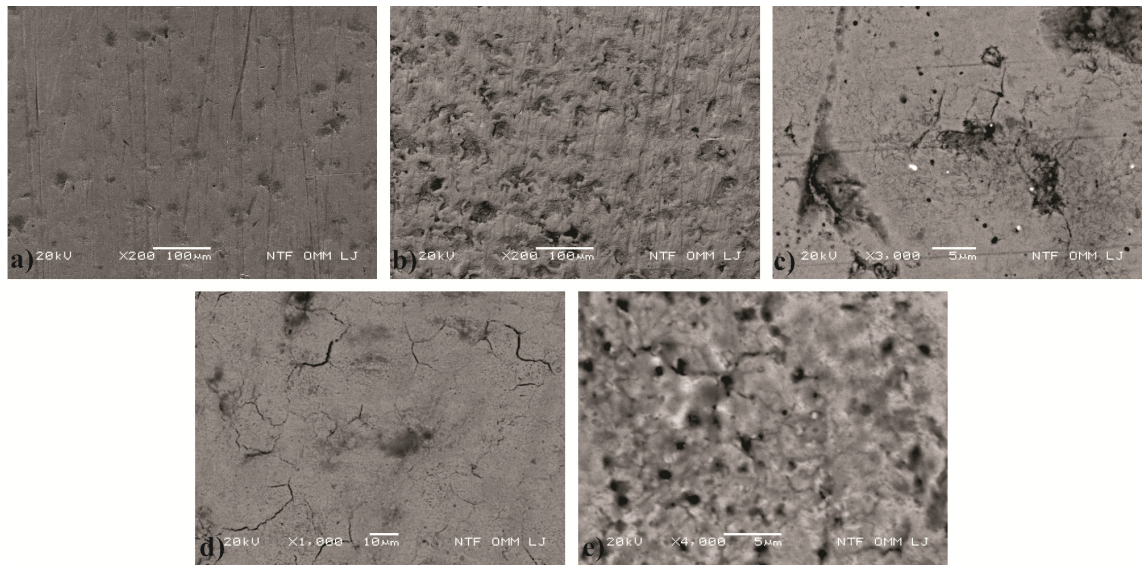

Figure 4: Main characteristics of the wear progress on the nitrided surface with the compound layer at two different contact pressures; low density islets removal of the compound layer at a low contact pressure (a) and increased density at a slightly higher contact pressure (b) after 60 min of testing (block 1), adhesional removal of the compound layer (block 1) (c), cracking of the compound layer (block 2) (d), occurrence of the cracking and adhesional removal at spots with increased porosity (block 2) (e), sliding direction $\leftarrow$.
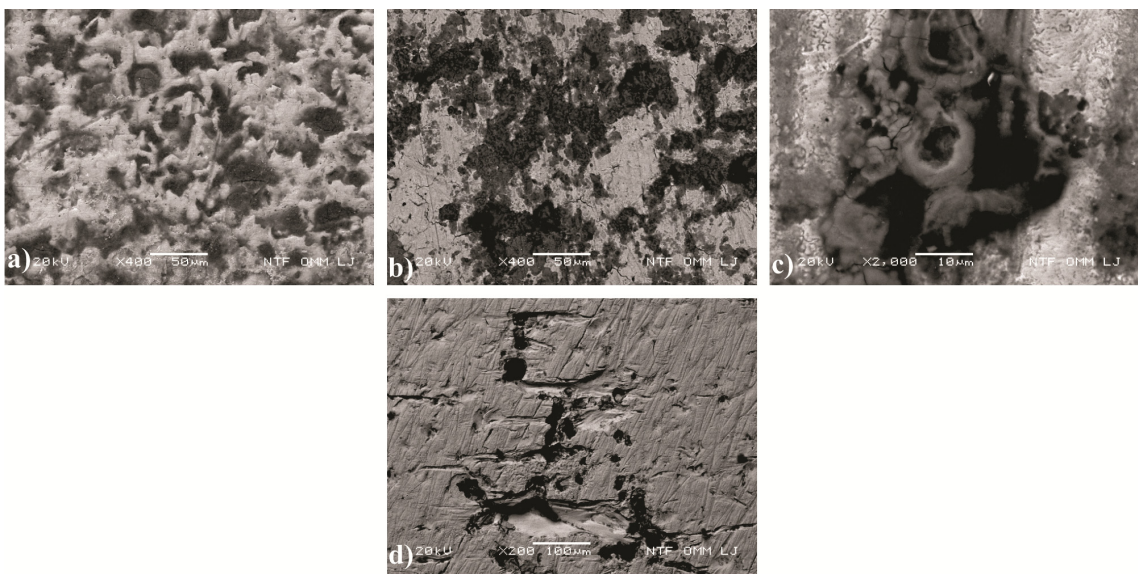

Figure 5: $\quad$ Progress of the wear on the nitrided surface of the tested blocks; high density islets removal of the compound layer for increased contact pressure (block 1, $\mathrm{t}=120 \mathrm{~min}$ ) (a), decreased removal of the compound layer for low contact pressure (block 2, t=120 min), detail of appearance of the tested surface (block 2) (c), in the sliding direction oriented removal of the nitrided layer after 180 240 min of testing (block 1) (d), sliding direction $\rightarrow$. 


\subsection{Analysis of the main characteristics of wear of extrusion dies}

Service time of die 1 was considerably lower (length of extruded profile $32775 \mathrm{~m})$ in comparison to die $2(55810 \mathrm{~m})$. Since other important parameters (extrusion ratio (ca. 47 and 50), extrusion exit speed (14 and $15 \mathrm{~m} / \mathrm{min}$ ), etc.) for die 1 and die 2, respectively, were similar, it can be assumed that the length of the bearing surface can play a decisive role in the die service time. Namely, the area of occurrence of the maximal normal and frictional stresses between the bearing surface and the extruded profile surface is at die 1 obviously near the exit edge. Moreover, relatively sharp exit edges are usually subjected to the danger of over-nitriding that decreases their properties (toughness). Consequently, in combination with the above mentioned increased loads accelerated removing on nitrided exit edge takes place which leads to a shorter service time of the die. Big differences in wear progress regarding the segments on the bearing surface were obtained. Thus, the cross-sections of all segments on both lateral sides (except right side on die 1) of the bearing surface, the exit edges exhibited a lower wear rate. On the other hand, most exposed to the wear were the upper and the lower segments of the bearing surface of both dies (see Figures 6-7). Two different modes at the initial wear progress on the exit (outlet) edge of the bearing surface of die 1 were observed. The first mode refers to the occurrence of the cracking of the exit edge (see Figure 6(a)) and consequently of its chipping (see Figure 6(b)). From such spots, the removal of material continues against the sliding direction (formation of furrows) and perpendicular to the sliding directions, i.e. around the edge of the die bearing surface perimeter as presented in Figure 6(c). Furthermore, indication of the formation of furrows (only in a few cases) starts also from other initial damage, i.e. extension of the initial crater (and not only from the exit edge chipping) in the sliding as well as against the sliding direction of the extruded profile (see Figure 6(d)). The fact that no typical high density adhesional removal of the compound layer (see Figure 5(a)) was observed indicates that a slightly lower contact pressure between the bearing surface and the extruded Al prevailed. Moreover, also in the sliding direction oriented removal of the compound layer (characteristic of a slightly increased contact pressure) was not emphasized in this case.

For the second mode of the initial wear progress, the occurrence of microcracking predominately almost parallel, but in a distance range of ca. 0.2-0.6 $\mathrm{mm}$, to outlet edge (see Figure 7(a) with cross-section on Figure 7(b)) is characteristic. Furthermore, Figures 7(c) clearly indicate that the removal of the nitrided layer begins at the occurrence of the crack and continues also towards the exit edge; namely, the narrow band of the nitrided layer at the exit edge is only partly removed (or even non-removed, see Figure $7(\mathrm{~d})$ ), while the material in the area range between the previous crack and slightly before the exit edge is completely removed. In the case where the initial cracking occurs relatively close to the exit edge its chipping occurs. Thus the appearance of cracking close to the exit edge can also be related to the occurrence of high normal and frictional stresses and not only to decreased properties of the nitrided layer. As mentioned above, the occurrence of the maximal contact pressure is, regarding the distance 
from inlet (or outlet) edge, not a constant value since it depends on Al flow, die design, extrusion technological parameters, etc. Moreover, the quality of the nitrided surface layer on the bearing surface can differ; consequently, different damage (at different times) can occur on the bearing surface.
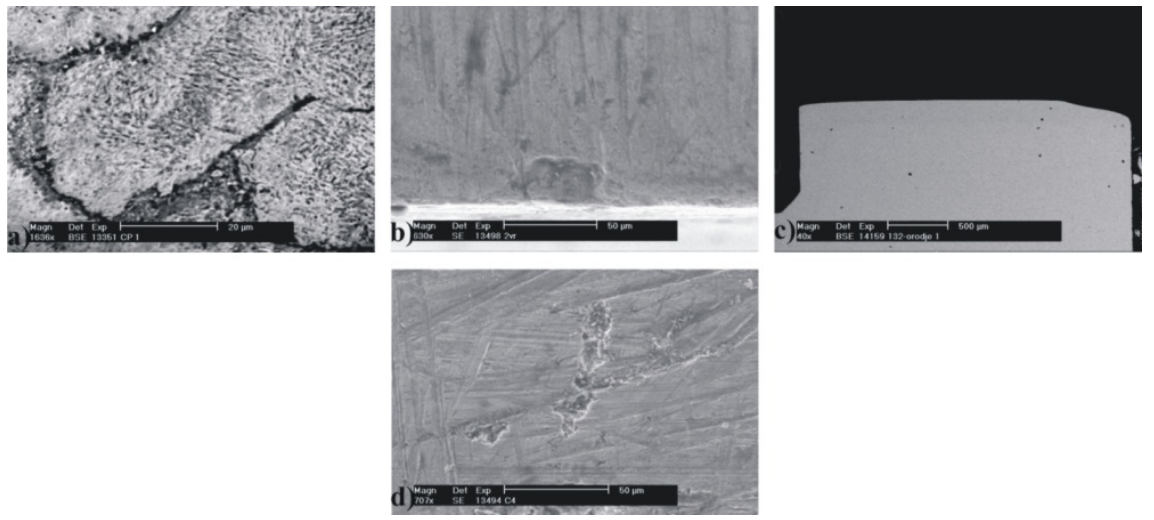

Figure 6: Main characteristics of the first wear mode on the die 1 with shorter bearing surface; cracking of exit edge (a), locally removed exit edge (b), cross-section of removed exit edge (c), extension of islet (d).
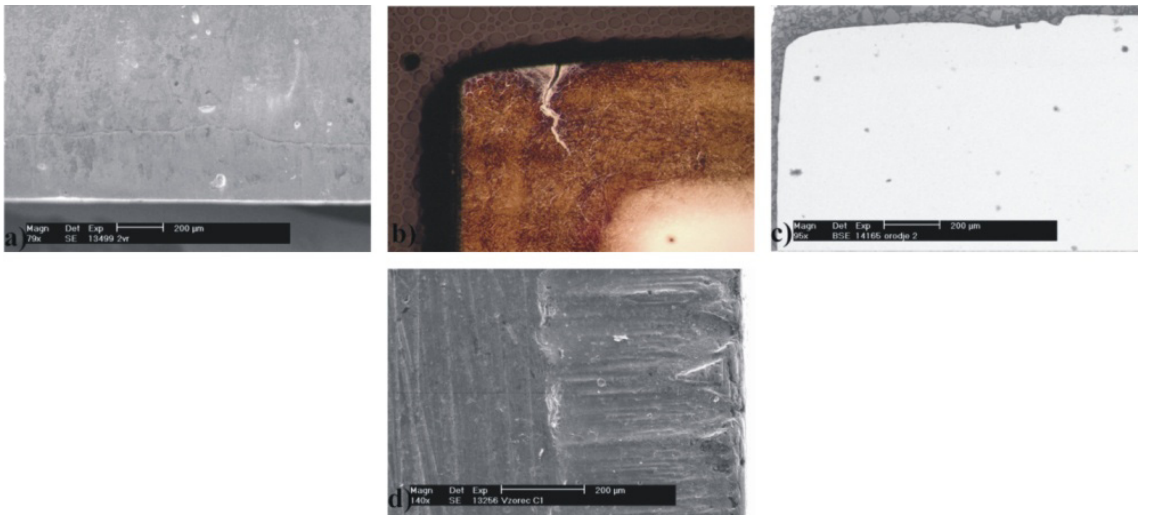

Figure 7: Main characteristics of the second wear mode on the die 1 with shorter bearing surface; occurrence of crack along exit edge (a), cross section of exit edge with crack (b), cross section of exit edge with removed compound layer (c), removed compound layer (d).

Similar to die 1, along the circumference of the bearing surface of die 2, different stages of the wear process can also be observed; thus Figure 8(a) shows the appearance of the wear progress on the lateral segment of die 2 where this achieved a considerably lower extent in comparison to the upper (or lower) 
segments. There the wear progress reached such an extent that it did not enable the required surface finish of extruded profiles; furrows approach the exit edge in the distance of about $0.3 \mathrm{~mm}$. The main characteristics are: (i) the occurrence of increased roughness of the compound layer as a consequence of emphasized high density adhesional removal of the compound layer (see Figure 8(b)) typically occurring at slightly increased contact pressures (see results of laboratory tests in Figure 5(d)); (ii) this leads to a so called formation of small craters (on spots with decreased quality of the compound layer) as well as to the initiation of formation in the sliding direction oriented furrows (see Figure 8(b)), since the shear strength of the compound surface layer is in this case considerably decreased; (iii) the next stage of the wear progress is the formation of shallow furrows which expand towards the exit as well as towards the inlet edges of the bearing surface. A considerable increase of the sizes of craters can also be observed.
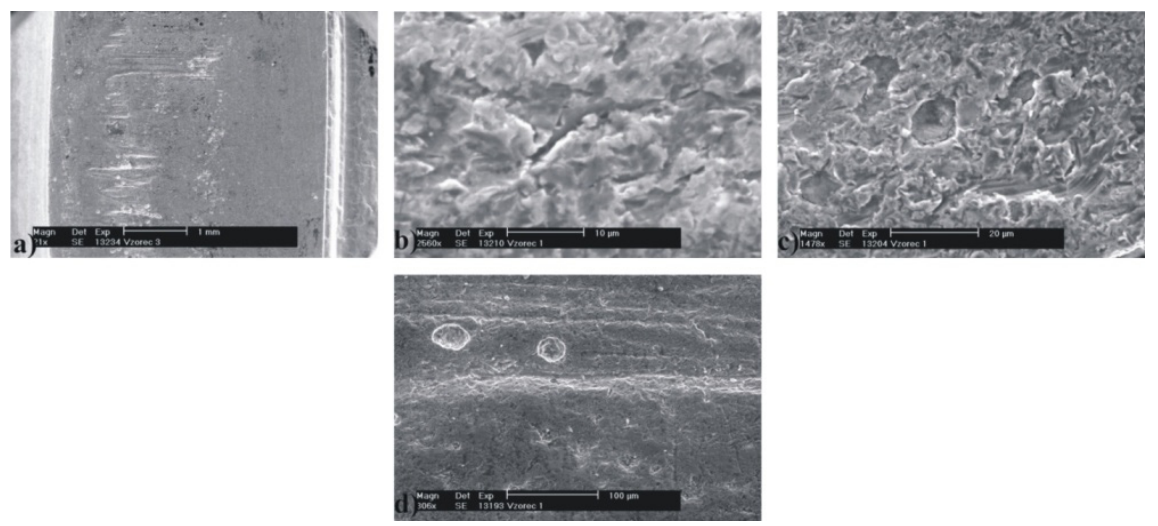

Figure 8: Main characteristics of the wear progress of the die 2 with longer bearing surface; typical appearance of wear (a), high density adhesional removal (b), formation of small craters, and initial stage of oriented removal of compound layer (c), formation of furrows (d).

Main damages on the coated die takes place predominately at the inlet but in lower degree also at the outlet edges of the bearing surface. For spot A (see Figure 3(c)) at inlet edges, this is presented on Figure 9(a) where coarse scratches perpendicular to the extrusion direction are visible. It is clear visible that they are the consequence of an inappropriate preparation of the inlet edge of die bearing surface; this leads to initial removal of $\mathrm{CrN}$ at the inlet edge in the shape of islets and their extending along the entire bearing surface towards the outlet edge (Figure 9(b)). Thus more attention should be paid to the preparation of the initial bearing surface as well as its inlet edge. In the central part of the die bearing surface it was observed that $\mathrm{CrN}$ coating on some spot was removed almost entirely (see Figure 9(c)), while predominately this did not suffer larger damages. Here should be emphasized that although locally $\mathrm{CrN}$ coating was 
entirely removed, this does not considerably decrease the surface finish of the extrudate, while the formation of furrow along the entire bearing surface (see Figure 9(b)) has a decisive influence on the surface finish of the extrudate. Thus, in order to efficiently utilize the wear resistance of coating the initial preparation as well as the maintenance of the edges should be carefully carried out.

Also on spot B (see Figure 3(b)) similar damages as at inlet edge on spot A (see Figure 9(a)) were observed. In the central part observed damages were predominately slightly smaller, while at outlet edge (see Figure 9(d)) considerably larger damages were observed in comparison to spot A (see Figure 3(c)).

Service time of nitrided and CrN coated die was approximately two times longer in comparison to only gas nitrided die. Thus $\mathrm{CrN}$ coated die is able to sustain considerably longer service time in case of improved preparation and maintenance of entire die bearing surface. More attention should be paid to the forming of radius of inlet edge where possible scratches and other damages should be avoided. Further, the radius of these gravures should be increased which will reduce the contact pressure and consequently also its crushing.
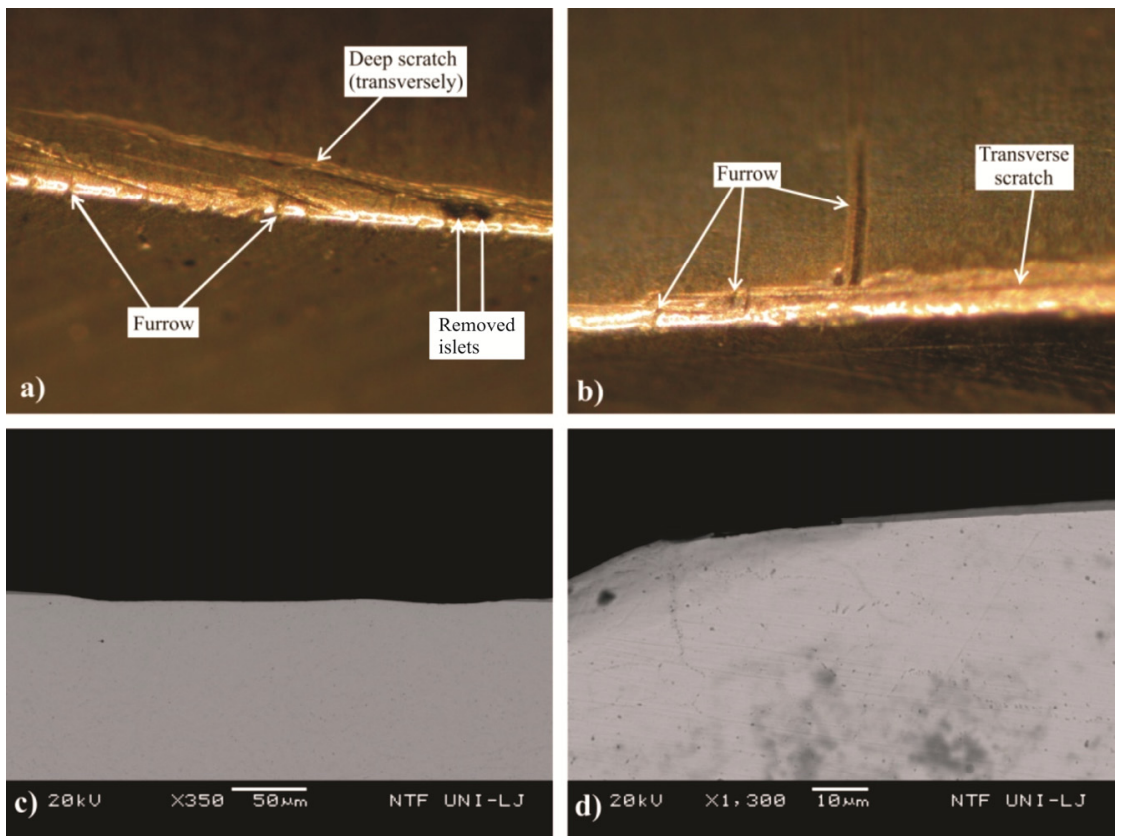

Figure 9: $\quad$ Occurrence of damages on inlet edge of the die bearing surface at spot A; tangential coarse scratches (a), formation of furrow, i.e. extending of initial micro-craters in sliding direction of $\mathrm{Al}$ profile (b), cross-section at removed $\mathrm{CrN}$ coating in central part (c) and at exit edge of bearing surface (d). 


\section{Conclusions}

From the analysis of the results obtained during wear tests on nitrided blocks carried out in a laboratory and the results of the wear analysis of the industrial hot extrusion dies, the following conclusions can be drawn:

- $\quad$ Prolongation of die service time of nitrided dies for Al hot extrusion can be achieved by improving the construction of dies with the aim to decrease contact pressure on the die bearing surface, improving the quality of microstructure of nitrided layer as well as determining the appropriate bearing surface length.

- At lower contact pressures, a lower density of removed islets of the compound layer as well as non-oriented removal of nitrided layer were observed; but this was the case in a later stage of the wear progress when applying a slightly higher contact pressure.

- $\quad$ At die 1, no typical high density of removed islets of compound layer was observed, which indicates that a slightly lower contact pressure prevailed on the bearing surface.

- Decreased quality of the compound layer accelerates its removal by the occurrence of additional mechanisms, i.e. cracking and accelerated removal on spots with an increased density of porosity.

- Bearing surface length of dies should be determined in relation to the area of occurrence of the maximal contact pressure.

- Inappropriate preparation of inlet edge of bearing surface of $\mathrm{CrN}$ coated die seems to be the main reason for formation of furrows which extend towards the exit edge of the bearing surface.

\section{References}

[1] T. Björk, J. Bergström, S. Hogmark: Tribological simulation of aluminium hot extrusion. Wear, 224, pp. 216-25, 1999.

[2] P. Matteis, G. Scavino, E. Quadrini, P. Perucci and D. Firrao: Damage of repeatedly nitrocarburised steel dies for aluminium extrusion. Surface Engineering, 25(7), pp. 507-516, 2009.

[3] YucelBirol: Analysis of wear of a gas nitrided $\mathrm{H} 13$ tool steel die in aluminium extrusion. Eng. Failure Analysis, 26, pp. 203-210, 2012.

[4] M. Pellizzari: High temperature wear and friction behaviour of nitrided, PVD-duplex and CVD coated tool steel against $6082 \mathrm{Al}$ alloy. Wear, 271, pp. 2089-2099, 2011.

[5] I. Schruff, A. Schindler, A. Kortmann: Die sachgerechte Prüfung und Wärmebehandlung von Warmarbeitsstählen. Härterei Tech Mitt., 53(3), pp. 139-146, 1998.

[6] T. Mori, N. Takatsuji, K. Matsuki, T. Aida, K. Murotani, K. Uetoko: Measurement of pressure distribution on die surface and deformation of extrusion die in hot extrusion of 1050 aluminium rod. J. Mater. Process Technol., 130-131, pp. 421-425, 2002. 
[7] M. Terčelj, G. Kugler, R. Turk, P. Cvahte, P. Fajfar: Measurement of temperature on bearing surface of industrial die and assessment of heat transfer coefficient in aluminium hot extrusion-a case study. Int. J. Vehicle Des., 39(1-2), pp. 93-109, 2005.

[8] M.P. Clode, T. Shepard: Formation of die lines during extrusion of AA 6063. Mater. Sci. Technol., 6, pp. 755-63, 1990.

[9] M. Terčelj, A. Smolej, P. Fajfar, and R. Turk: Laboratory assessment of wear of nitrided surfaces of dies for hot extrusion of aluminium. Tribol. Int., 40, pp. 374-384, 2007.

[10] T. Björk, R. Westergård, S. Hogmark: Wear of surface treated dies for aluminium extrusion - a case study. Wear, 249, pp. 316-323, 2001.

[11] D. Lidtke, U. Baudis, J. Bosslet, U. Huchel, H. Klümper-Westkamp, W. Leche, H. J. Spies: Wörmebehandlung von Eisenwerkstoffen: Nitrieren und Nitrocarburieren, ISBN 3-8169-2416-6, Expert Verlag, 2006.

[12] M. Hernandez, M.H. Staia, E.S. Puchi-Cabrera: Evaluation of microstructure and mechanical properties of nitrided steels. Surface \& Coatings Technology, 202, pp. 1935-1943, 2008.

[13] T. Björk, J. Bergström, S. Hogmark: Optimization of nitriding parameters for extrusion dies, evaluated in an extrusion simulation. In: Seventh int. aluminium extrusion technology seminar, 2, pp. 317-325, 2000.

[14] K.B. Müller: Deposition of hard films on hot-working steel dies for aluminium. J. Mater. Process. Technol., 130-131, pp. 432-437, 2002.

[15] S. S. Akhtar, A. F. M. Arif, Bekir Sami Yilbas: Evaluation of gas nitriding process with in-process variation of nitriding potential for AISI H13 tool steel. Int. J. Adv. Manuf. Technol., 47, pp. 687-698, 2010.

[16] J. Baranowska, K. Szczecinski, M. Wysiecki: Increasing of gas nitriding kinetics via surface pre-treatment. Surf. and Coat. Techn., 151-152, pp. 534-539, 2002.

[17] M. Vilasecaa, S. Molasa, D. Casellasa: High temperature tribological behaviour of tool steels during sliding against aluminium. Wear, 272, pp. 105-109, 2011. 